\title{
About Lamotrigine and Its Hepatic Effects
}

Dear Sir:

May 15, 2005

Dr. James W. Jefferson's article "Lamotrigine in psychiatry: pharmacology and therapeutics" (CNS Spectr. 2005;10(3):224-232) reviewed effects and use of lamotrigine in the psychiatric population in a previous article.' Lamotrigine is a promising agent for bipolar disorders and research on use in other psychiatric disorders are still carried on. It is generally well tolerated but its hepatic effects still appear to be unclear.

Dr. Jefferson scems to have overlooked the hepatic side effects. Although hepatitis associated with the drug is believed to be rare, at least 10 cases of hepatic side effects, one of which was in a psychiatric patient, have already been reported. ${ }^{2,3}$ Hepatic side effects ranged from mild liver enzyme elevation to fatal hepatitis., The possible toxicity was mostly seen in children but adult cases were not exception either in monotherapy or add-on regimens. The causes of drug interactions with clozapine ${ }^{1}$ and recently with risperidone $e^{4}$ with lamotrigine suggests somehow an effect of lamotrigine on liver metabolism, although the drug is believed not to "go through" the liver. Routine monitoring of hepatic function is told not to be necessary, ${ }^{1}$ but clinicians should be aware of this when administrating lamotrigine to patients.

Yours Sincerely, Salih Selek, MD, and Savas A. Haluk, MD

\section{REFERENCES}

1. Jetferson JW. lamotrigine in psychiatry: pharmacology and therapeutics. CNS Spectr. $2005 ; 10: 224-232$

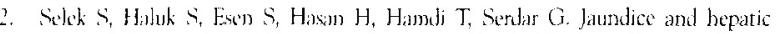
encyme indection dering lamotrigine therapy an a hipolar II patient. Int J Psychiary ('im l'ract. 2005;9:65-67.

3. Filyik M, ohereiri R, Mikati M. Potential hepatentexicity of lamotrigine. Pediatr Neurd. 2000:22:49-52.

4. Bienentres S1), Kommuller KT. Incrense in rispertume plastna level wirh lamotrigine Am J Psuchiatry. 2005;162:811-812

Dr. Selek is resident and Dr. Haluk is associate professor both in the Department of Psychiatry at Gaziantep University Hospital in (scizicutep), Turkey.

Disclosure: The authors do not have an affiliation with or financial interest in any organization that might pose a conflict of interest.
I thank Drs. Selek and Haluk for expanding further on my brief discussion of hepatic dysfunction associated with lamotrigine. Their case report and the risperidonel lamotrigine case report were published after my review had gone to press; otherwise, they would have been added to the references. Keeping up with the literature is a never-ending challenge-it is clear that Drs. Selek and Haluk have risen to the occasion.

Sincerely,

James W. Jefferson, MD

Madison, Wisconsin

Please send "Letters to the Editor" to: CNS Spectrums, clo Jack M. Gorman, MD, 333 Hudson St., 7th Floor, New York, NY 10013; E-mail: SB@mblcommunications.com 